\title{
DRASTIC for Groundwater Vulnerability Assessment using GIS: A Case Study in Laylan Sub-Basin, Kirkuk, Iraq
}

\author{
Najem Khaled Najem Abo-Khomra ${ }^{1, *}$, Omer Sabah Ibrahiem Al-Tamimi ${ }^{1}$ and Arsalan Ahmed \\ Othman $^{2,3}$
}

Department of Applied Geology, College of Science, University of Kirkuk, Kirkuk, Iraq Iraq Geological Survey, Al-Andalus Square, Baghdad, Iraq

Department of Petroleum Engineering, Komar University of Science and Technology, Sulaimaniyah, Iraq Correspondence: najemkhaled738@gmail.com

\begin{abstract}
Received:

4 November 2021

Vulnerability evaluation to determine more susceptible to contamination regions has

Accepted:

20 November 2021 played a significant role in urban planning and resources management. Our study is the first study comes to use the DRASTIC model assessing the vulnerability areas of the Laylan sub-basin. An extra aim is to prove the integration between DRASTIC and the geographical information system for risk estimation of groundwater discrimination. Seven

Published:

28 February 2022 DRASTIC factors have been utilized to maintain the groundwater quality in the study area. These parameters were prepared and analyzed using geographical information system software. Each parameter was got a weight according to its importance. The sum of these parameters produced a final map showing the areas of vulnerability in the region. The final map contains five vulnerability zones distributed in the Laylan sub-basin. The northern and northwestern parts of Laylan sub-basin were characterized as very high and high vulnerability; whilst the central part was dominated as very low and low vulnerability.
\end{abstract}

Keywords: Laylan Sub-basin; DRASTIC; GIS; Vulnerability

\section{Introduction}

Laylan sub-basin is situated within the north of Iraq far to the north $255 \mathrm{~km}$ of Baghdad. It is located in the southeast of Kirkuk city $\left(44^{\circ} 18^{\prime} 30^{\prime \prime} \mathrm{E}-44^{\circ} 40^{\prime} 30^{\prime \prime} \mathrm{E}\right.$ and $\left.35^{\circ} 7^{\prime} 30^{\prime \prime} \mathrm{N}-35^{\circ} 29^{\prime} 30^{\prime \prime} \mathrm{N}\right)$. Kirkuk structure bounded the study area from the northeast side, while the southwest part of Laylan sub-basin bounded by the Jambur anticline. Khasa Chay seasonal stream makes the northwest and west boundary, while it bounded from the south and southwest by an ephemeral stream named Mamsha stream. The topography of the area is plain; hills are scattered in the southwest part towards the Jambur anticline, between $243 \mathrm{~m}$ and $402 \mathrm{~m}$ altitude above sea level. The area is covered $278 \mathrm{~km} 2$ (Fig.1). The groundwater and surface water are considered as basic sources, which are used for many purposes.

Due to the shortage of surface water, which is used for drinking, irrigation and the food industry, there is an increasing in the groundwater demand (Smith et al., 2016). Normally, the groundwater recharge is lower than its pumped out. This makes a trouble in feeding, extracting, and lowering of the subsurface water (Chenini \& Mammou, 2010). A measurement of subsurface water is important for the

DOI: $10.46717 /$ igj.55.1B.7Ms-2022-02-23 
sustainable management, which is going on often by using Remote Sensing (RS) and Geographic Information System (GIS) (Thapa et al., 2017; Nasir et al., 2018). RS, maps, and statistics models are generally applied to get information about potential subsurface water zones (Selvam et al., 2015; Sener et al., 2005; Magesh et al., 2012). Therefore, RS and GIS have used as an essential technique to create existing subsurface water resources (Jha et al., 2007). However, prevention is better than cure, so problems are searched before they occur in order to avoid treatment in the future, since treatment is expensive and long-term (Aller et al., 1987).

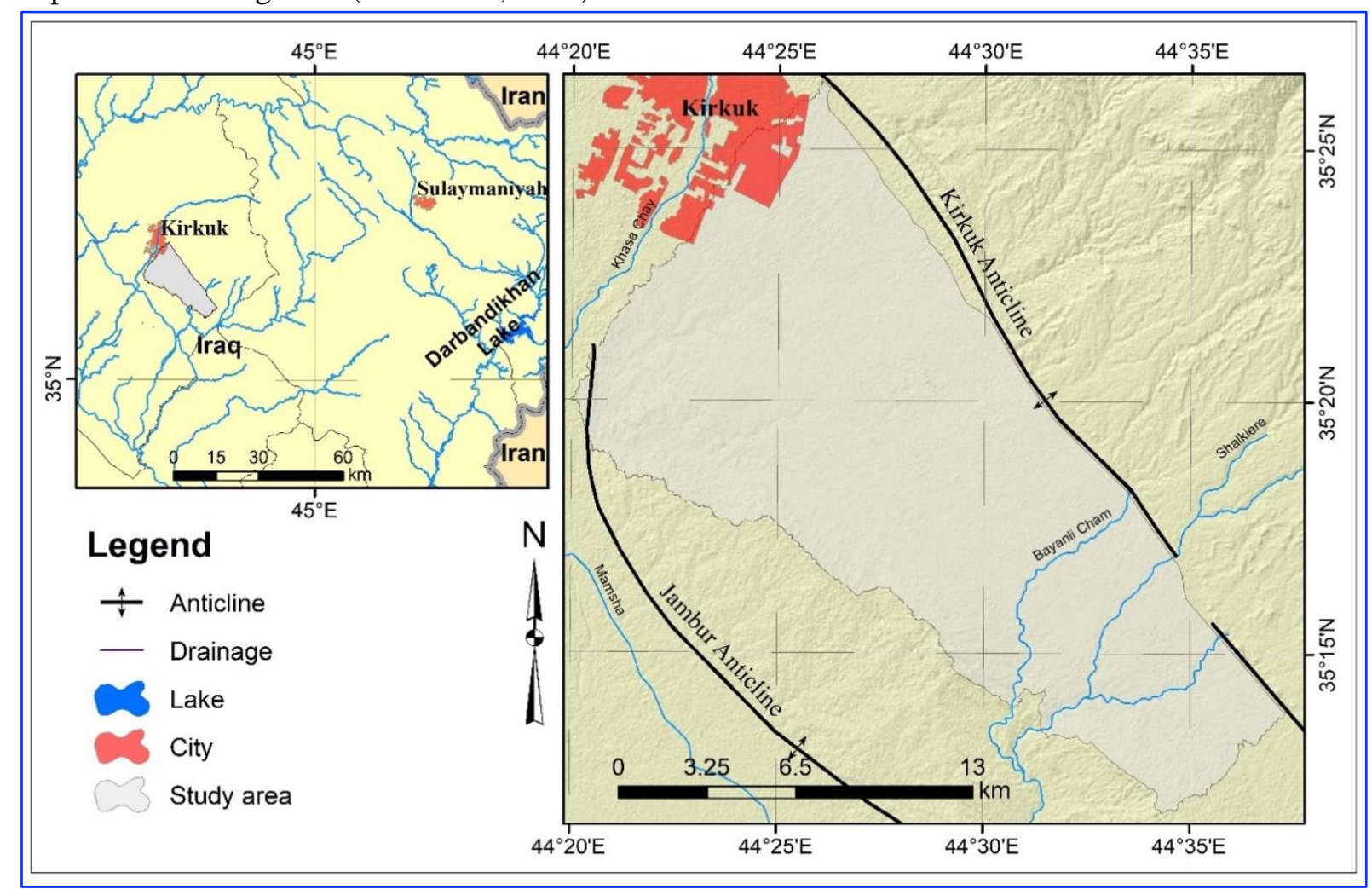

Fig.1. Location of the Laylan sub-basin

The DRASTIC (depth to water (D), net Recharge, Aquifer media (R), soil media (S), topography (T), impact of vadose zone (I), and hydraulic conductivity (C)) model is utilized for finding vulnerabilities in the porous aquafers frequently and proven effective in this area (Aller et al, 1987). There is no study dealt with DRASTIC model to estimate the vulnerability zones for groundwater within Laylan sub-basin. Two studies, within the Kirkuk Governorate, used DRASTIC model to evaluate the vulnerable zones for groundwater. Both of these studies located in the north of Laylan sub-basin, these are (Al- Hayali et al., 2021) and (Al-Gburi et al., 2020). Globally, the DRASTIC model has been applied by several studies model, such Kozlowski and Sojka (2019). The objective of our work is to estimate subsurface water vulnerability classes in Laylan area utilizing GIS and DRASTIC.

\section{Materials and Methods}

The Environmental Protection Agency (USEPA) is developed a method that deliver fixed or uniform assessment to pay pollutants from ground water and protect, this method is DRASTIC (Aller et al., 1987). The groundwater vulnerability used the $D, R, A, S, T, I$, and C parameters that represent all geological and hydrological factors, which effect groundwater vertical profiles flow of in a region. To define investigated region, each criterion is allocated from 1 to 10 range value scale (r), where the 
smallest value is less sensitive region to pollution (Table 1). Depend on a mathematical equation, all of these criteria are combined. Moreover, a value is given to each specific parameter according to the degree of importance of this parameter, where there is a specific scale ranging from 1-5 according to the importance, the most important value is taken from this scale, and the areas of vulnerability can be found through the following equation (Aller et al., 1987):

$$
\text { DRASTIC }=D_{r} D_{w}+R_{r} R_{w}+A_{r} A_{w}+S_{r} S_{w}+T_{r} T_{w}+I_{r} I_{w}+C_{r} C_{w}
$$

where $\mathrm{w}$ is weight and $\mathrm{r}$ are the rank.

Table 1. DRASTIC favtors' weight (Aller et al.,1987)

\begin{tabular}{cc}
\hline DRASTIC Parameters & weight \\
\hline D & 5 \\
R & 4 \\
A & 3 \\
S & 2 \\
T & 1 \\
I & 5 \\
C & 3 \\
\hline
\end{tabular}

We prepared all maps and parameters using ArcGIS 10.6. The SRTM-DEM 30-m resolution was used to represent the T. Soil raster were obtained from Harmonized World Soil Database. The soil raster data is of a $\sim 1 \mathrm{~km}$ resolution (Othman et al., 2020 and Othman et al., 2021). The rest data (D, R, A, I, and C) of the depth were collected through the field. Some of these data were collected from previous studies and from the wells archive of the groundwater drilling department in Kirkuk. After the data collection, the data were entered into the ArcGIS. To improve the resolution of the HWSD data, we converted its raster structure into vector (points). Then, the vector (points) data were distributed using inverse distance weight (IDW) method. The other parameters, that have vector structure, have been rasterized using IDW, too. The final resolution of all these layers were $30 \mathrm{~m}$. Then, all these parameters were merged with each other by the program and producing the final map that shows the areas of weakness in the area the Table 1 shows the importance values for each parameter Fig. 2 shows how this method works (Machdar et al., 2018).

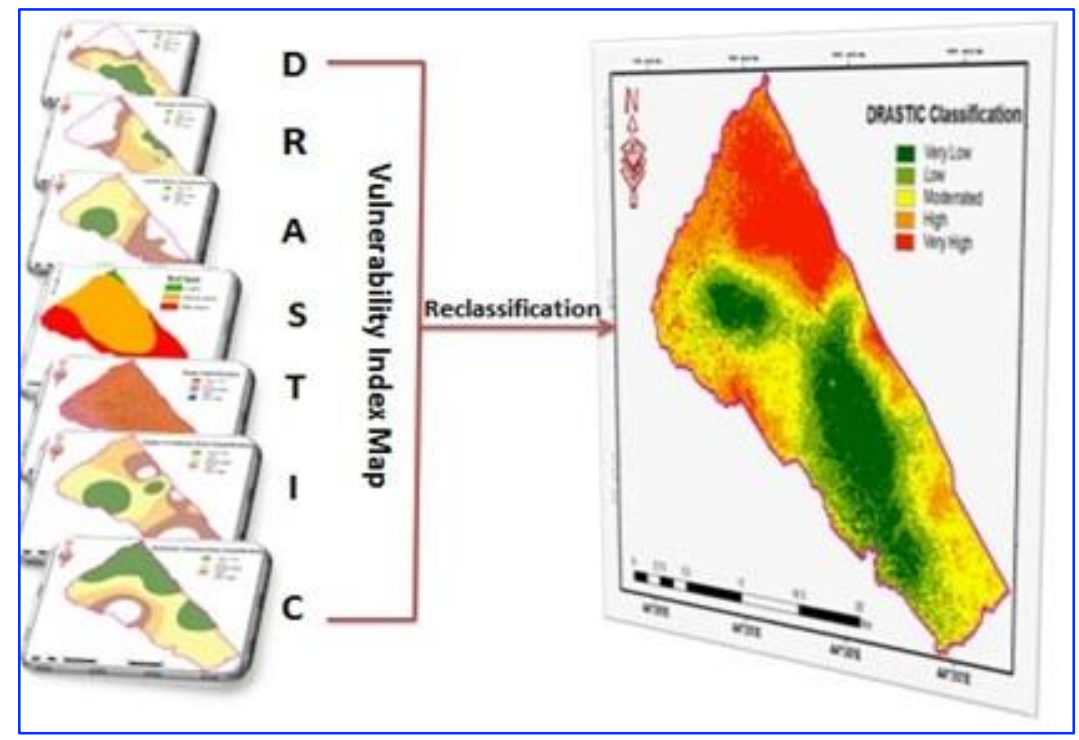

Fig.2. Evaluation layer of the seven parameters and groundwater vulnerability 


\section{Results}

Soil is that layer forms in the upper part of the earth's surface and that extends to a depth of $2 \mathrm{~m}$ as a maximum for the soil in the ground. (Fig. 3A), the soil raster of Laylan sub-basin, which otained from Food and Agriculture Organzation (FAO). The database of the soil types and their areas and ratings can be found in Table 3. As shown in Figs. 3A and 3B., three soil types appeared in Laylan sub-basin, which are loam (lies in the northwestern part of the study area), sandy loam (located in the centeral and northwestern parts of the study area), and siltiy Loam (located in the south and western parts of Laylan sub-basin) (Table 3).

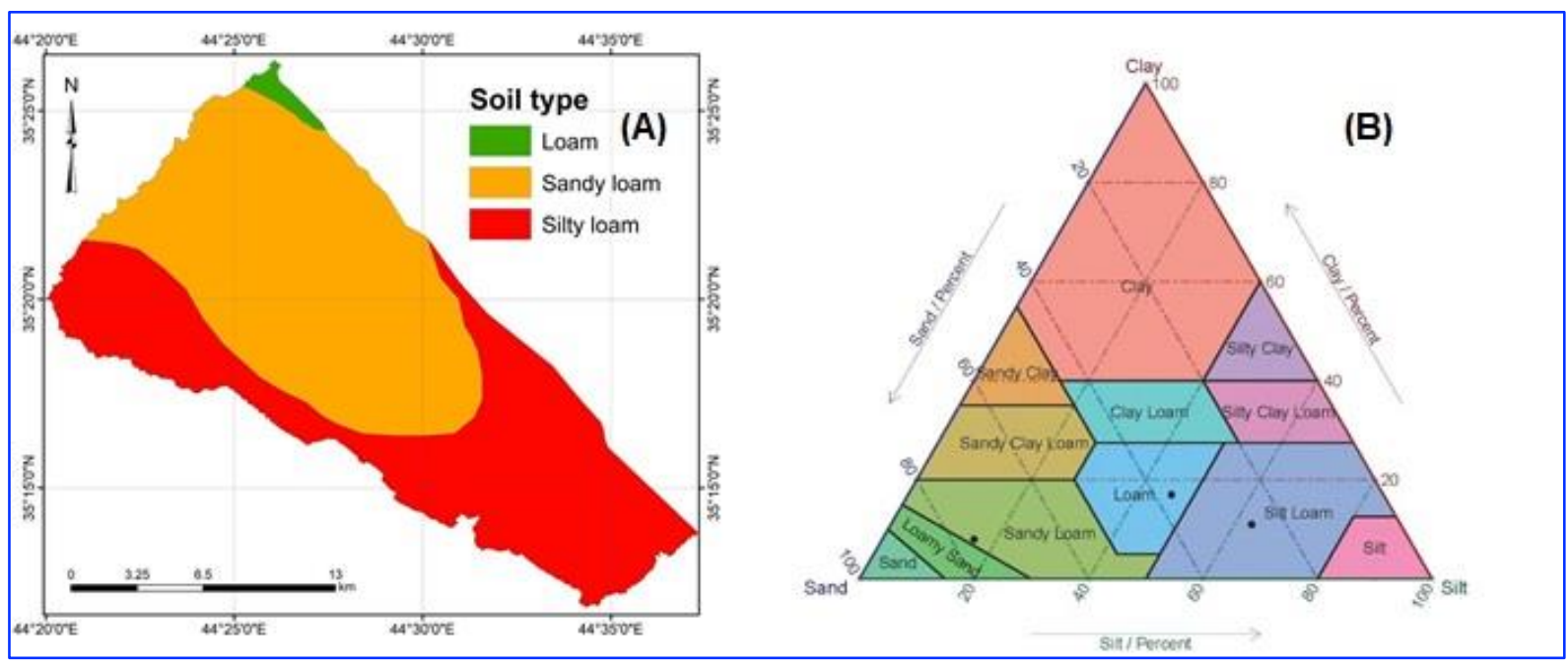

Fig. 3. (A) Soil map and (B) soil texture classification of the study area

Table 3. The texture of the three soil types in the study area

\begin{tabular}{llllllll}
\hline & Gravel\% & Sand\% & Silt\% & Clay\% & Extension area $\left(\mathbf{k m}^{2}\right)$ & Extension area (\%) & Rating \\
\hline Loam & 4 & 37 & 46 & 17 & 5.4 & 1.9 & 5 \\
Silt loam & 21 & 76 & 16 & 8 & 124.4 & 44.7 & 4 \\
Sandy loam & 22 & 26 & 63 & 11 & 148.3 & 53.3 & 5 \\
\hline
\end{tabular}

Fig. 4A represents the depth to groundwater layer. Generally, It shows that the depth to the groundwater is decreased to the northwestern of the study, which means that the vulnerability in the northeastern part is very high, as far as this parameter is concerned while it is very low in the southwestern part. Table 4 indicates the experimental pumping data that was relied upon in preparing the recharge map, which is used to create the recharge distribution map (Fig. 4B), where the high vulnerable zone located in the nothwestern part, while the very low vulnerable zone located in the eastern part. Fig. 4C shows the aquifer meadia distribution in the Laylan sub-basin, where the high hvulnerable zone located southeastern part of the study area, while the very low vulnerable zone located in the northeastern part. Fig. 4D shows the topographic becomes clear that most of the study area is of a flat nature, with low slope areas in the southern part of Laylan sub-basin. Fig. 4E shows the impact vadose zone map of the Laylan sub-basin, where the high vulnerable zone located in suothwaestern and some parts in nourth but very low vulnerable zone located in the northeastern part. Fig. 4G shows hydraulic conductivity distribution in study area, which means that the vulnerability in the south part is very high, while it is very low in the nourth and nourtheastrn part. Table 5 indicates the weighting and 
rating of all parameters in this DRASTIC model. The rating in Table 5 were used to prepare the abovementioned DRASTIC maps.

Table 4. Rating \& weighting of all parameters (Aller et al.,1987)

\begin{tabular}{|c|c|c|c|}
\hline \multicolumn{2}{|c|}{ Depth to water Wight $=5$} & \multicolumn{2}{|l|}{ Aquifer media $($ weight $=3$ ) } \\
\hline Rating & Depth to water (m) & Sand and gravel & 8 \\
\hline 10 & Less than 1.5 & Sand with some clay/ silt & 6 \\
\hline 9 & $1.5-4.5$ & Clay and silt with some sand/ gravel & 4 \\
\hline 7 & $4.5-9$ & Clay and silt & 2 \\
\hline 5 & $9-15$ & $\mathrm{~T}($ Slope $\%$ weight $=2)$ & \\
\hline 3 & $15-23$ & Slope \% & Rating \\
\hline 2 & $23-30$ & $0-2$ & 10 \\
\hline 1 & More than 30 & $2-6$ & 9 \\
\hline \multicolumn{2}{|c|}{ Recharge (m) Weighting 4} & $6-12$ & 5 \\
\hline Ranking & Range & Impact vadose zone (weight $=5$ ) & \\
\hline 1 & $0-50.7$ & Impact vadose zone & Rating \\
\hline 3 & $50.8-101.5$ & Sand /gravel & 8 \\
\hline 6 & $101.5-177.7$ & Sandy clay & 4 \\
\hline 8 & $177.8-253$ & Silt/clav & 3 \\
\hline 10 & More than 254 & silt /cray & 3 \\
\hline \multicolumn{4}{|c|}{ Hydraulic Conductivity (weight $=3$ ) } \\
\hline Less than 4.0 & & 1 & \\
\hline $4-12$ & & 2 & \\
\hline $12-30$ & & 4 & \\
\hline $30-40$ & & 6 & \\
\hline $40-80$ & & 8 & \\
\hline
\end{tabular}

Table 5. Pumping test and recovery of the seven wells in study area

\begin{tabular}{cccc}
\hline Well & K (m/day) & K (m/day) & K (m/day) Av. \\
\hline 1w & 1.33 & 0.78 & 1.06 \\
2w & 2.17 & 2.27 & 2.22 \\
5w & 1.58 & 1.02 & 1.30 \\
18w & 3.19 & 4.76 & 3.98 \\
20w & 6.36 & 1.28 & 3.82 \\
30w & 18.14 & 16.6 & 17.37 \\
11w & 1.8 & 0.9 & 1.35 \\
& 4.44 & & \\
\hline
\end{tabular}

The DRASTIC map (Fig. 5) shows the vulnerability index zones of Laylan sub-basin. The low vulnerability areas were concentrated in the cinteral and south of Laylan sub-basin, the zones of high vulnerability were found in the northern and northwestern parts of Laylan sub-basin, while the zones 
with the intermedat vulnerability is spread in most of Laylan sub-basin, and. Table 6 exhibits the importance of vulnerability in general.

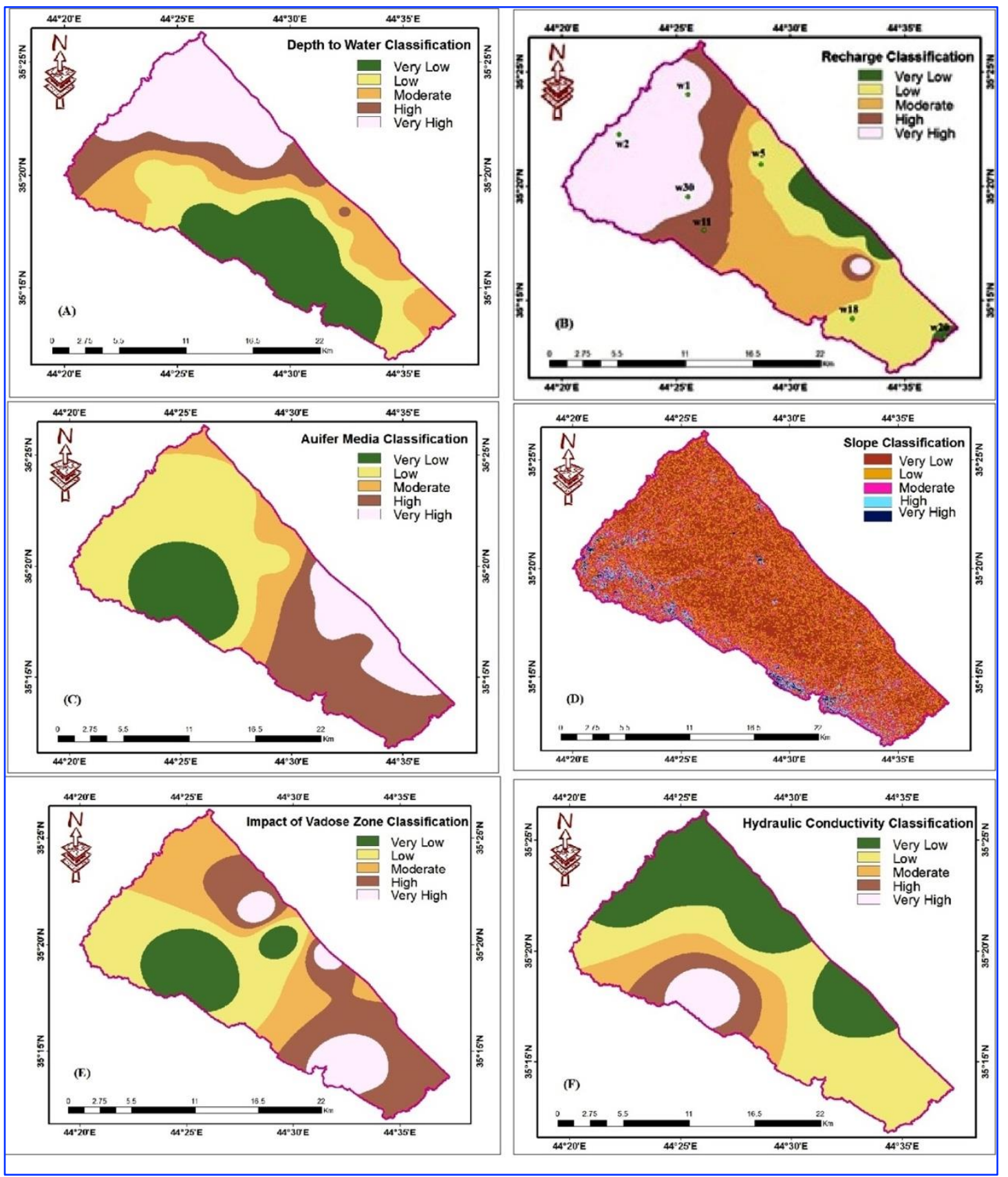

Fig.4. parameters of DRASTIC Model

Table 6. Ranges of the vulnerability using DRASTIC method

\begin{tabular}{ll}
\hline \multicolumn{2}{l}{ Ranges of vulnerability using DRASTIC method based on Aller et al., (1987) } \\
\hline Index of vulnerability & Vulnerability degree \\
$75.2-81.5$ & Very low \\
$81.5-85.1$ & Low \\
$85.1-88.4$ & Medium \\
$88.4-91.7$ & High \\
$>91.7$ & Very high \\
\hline
\end{tabular}




\section{Discussion}

\subsection{DRASTIC Parameters}

As it is known, the lower the depth of the water, the more dangerous it is; because the pollutants reach the groundwater in the least time. Fig. 4A shows that the area located southwest of the study area (green-colored zone) is critical. This area could be contaminated due to the low groundwater depth, while the white color is the deepest and safest. Two methods were relied upon to calculate the recharge zones. The First method is the analysis of the elements of the climatic water balance for the last 30 years. The second method is the method of balancing the mass of chloride. Both methods show convergence in the results. The amounts of groundwater recharge for the first and the second methods are $70.78 \mathrm{~mm}$ and $68.50 \mathrm{~mm}$, respectively. Despite the convergence between the results, we used the average of these two methods, which is $69.64 \mathrm{~mm}$. The recharge map (Fig. 4B) clearly shows that the more we head towards the southwest, the value of the vulnerability increases in the study area due to the effects of the permeability and porosity.

Soil represents the first layer of the vadose zone or the so-called unsaturated zone. The soil grains differ from one place to another due to the different sources that make up the soil and the way this soil was formed. This is a simple illustration of this factor that is used in this model (DRASTIC) to define vulnerability zones in the study area. The soil is a significant factor in term of protecting the aquifer from pollution. During recharge this layer absorbs pollutants and influences infiltration into subsurface water, thus retarding contamination (Al-Gburi, 2020; Kiely, 1998). The soil in the study area is divided into three areas of evidence that occupy an area of the study area, while the third area occupies a portion that runs from the northwest direction in the extreme limits of the study area. The first part is loam covers about $5.4 \mathrm{~km} 2(1.9 \%$ of the study area), the second part is silty loam covers about $124.4 \mathrm{~km} 2$ ( $44.7 \%$ of the study area), and the last part is sandy loam cover about $148.3 \mathrm{~km} 2(53.3 \%$ of the study area). This factor is one of the important factors in a DRASTIC model. It is the first factor that affects water infiltration. The type of these deposits has been identified using soil texture classification which depends on the ratio of the sand, silt, and clay within the soil. Fig.3 is explained the distribution of the sand and clay and silt and shows types of texture. Table 3 showed the percentage of the clay, silt, and sand collected from the Harmonized world soil database (FAO, 1971). Table 3 rated this parameter, while Fig. 3 explained this factor in the study area as the fabric with fewer pores, impedes the movement of water.

The topography (slope) layer was constructed from Digital elevation Model (DEM). The gradient slope was then extracted from the DEM in ArcGIS. It was classified into five classes. Flat and low slopes areas supposed as high rates because they slow down the runoff, then more time for the contaminants to percolate down to reach the subsurface water, while the steep slopes areas increase the runoff, led to wash out the pollution, hence are supposed as low rates (AL- Hayali et al., 2021; Babiker et al., 2005). when looking at the map in Fig. 4, it becomes clear that the region is divided into five zones. These five zones are categorized as very low, medium, high, and very high. Prevailing in the region is very low and low in the study area. This means that the rainwater will take enough time to penetrate into the groundwater, as the nature of the land is almost flat in most of the studied area. Conversely, in highland or rugged areas where rainwater is transported by gravity away from the aquifer. Table 6 shows the rating of this parameter.

The unsaturated area through which the water passes through its path to the groundwater, so all its details must be known in terms of depth, rocks, and permeability (Rasheed, 2019). An estimate of the amount of water that reaches the aquifer from all the amount of water entering this zone. Some parts of this water evaporated and another part that is kept in it this zone. While not all of the water reaches the 
aquifer. five zones in the region that differ in locations and the degree of their ability to pass water through them. The first zone band consists of clay, silt, and mud, which have high porosity and represent the very low and low classes. However, its permeability is low, as this range extends and which occupies the southwestern part extending from the center of the study area in this direction. This range is hindered by the movement of water or in other words, the water takes a long time within this range until it reaches groundwater. The second zone (moderate and high) covers the largest area within the study area. it represents the rocky area, which is composed of silt, sand, gravel, and mud. The permeability of this zone is higher than its previous one. The third zone (very high), which composed of sand, and gravel. It is not mixed with silt and clay; therefore, the permeability of this zone is higher than the previous zones. Therefore, the movement of water in it quickly and easily and the extension and presence of this range is within the study area in the southeastern part and a few areas in the part north and northwest parts. Table 6 is explained the weighting of this parameter.

Permeable, or so-called secondary porosity, which is those voids between the grains of taken rocks or deposits that allow the fluid to pass through it the ease of movement and passage of fluids through these voids located between the grains of rocks. Or in other words, the permeability of the rock is the capacity to transmit water under various pressure and is estimated by the rate at which it will transmit water through a unit cross-section under unit pressure various per unit distance (Martínez-Bastida et al., 2010; Lathamani et al., 2015). To identify this factor or this feature in the study area, it was necessary to conduct a pumping test for a group of wells in the area to identify and study a set of hydrological properties of the aquifer, including this feature, as well as the conductivity and the groundwater basin storage factor and other anther properties. A simple explanation of the pumping test experiment is to pump water from a well. And measure the water level in the well to continue with the time of pumping. Until the water level is stable, that is, when the pumping is equal to the feeding of the well. This study was based on seven wells present in the region where these wells were chosen to cover all the study areas and that these data were obtained through previous studies of the region by (Rasheed, 2019). These data were extracted, approved, and mapped this factor using the IDW method within ArcGIS. Table 4 shows the pumping test and recovery recorded of the seven wells, and Fig. 4F shows hydraulic conductivity in the study area.

\subsection{DRASTIC Map}

Fig. 5 shows the zones of vulnerability in the Laylan sub-basin, it becomes clear that the northwestern zones have a high vulnerability, and the reason for this is the aquifer rock and the vadose zone in this area, which is highly permeable, as well as the soil of this area, which allows water filtering through it easily. This area is almost having a flat slope; therefore, the water takes enough time to be filtered the ground, thus the possibility of pollutants reaching greater. The low vulnerability area, which is located in the central of Laylan sub-basin, is characterized by rocky nature. where it has less permeable than the previous one. These areas easily impede the entry of water into the ground, and therefore water moves from these areas to other areas, since the slope is higher in these areas than the previous one. Therefore, pollutants move before penetrating the groundwater, while areas with medium vulnerability have medium permeability rock characteristics.

\subsection{DRASTIC Validation}

We validated the groundwater vulnerability model by selecting samples from nine wells used for Total Dissolved Solids (TDS) concentrations to validate the results obtained by the DRASTIC model. The TDS represents the sum of all the substances, organic and inorganic, and dissolved in water. Several studies have used TDS in water to validate the groundwater vulnerability, such as Bera et al., (2021); 
Le et al. (2021). Fig. 6 shows the relation between the TDS and the vulnerability, where the groundwater vulnerability has a direct relationship with the TDS. T It has been observed from the correlation analysis between the groundwater vulnerability and the TDS is $\sim 0.85$, which indicates a strong positive correlation.

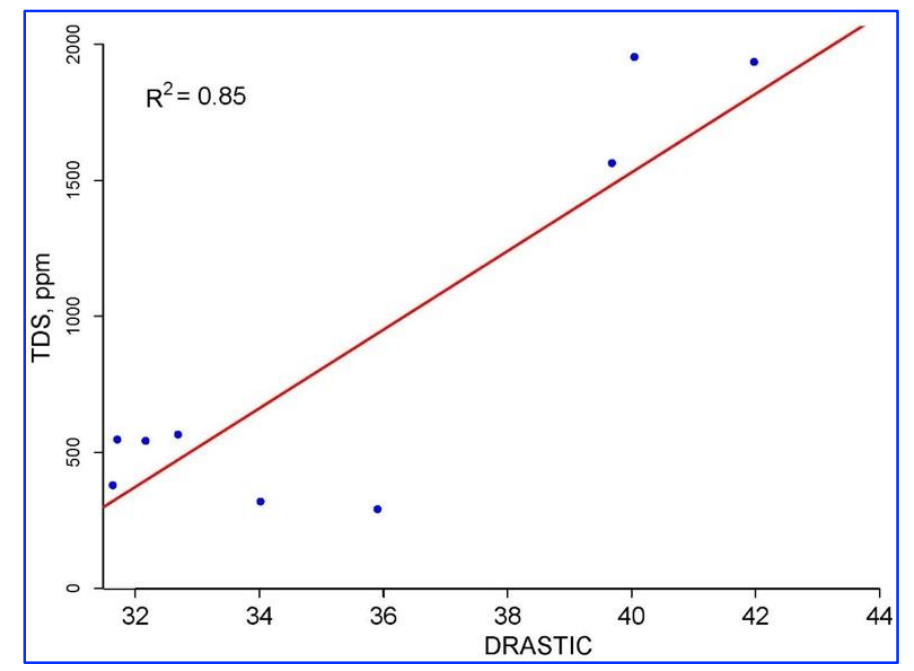

Fig. 6. The correlation analysis between the groundwater vulnerability and the TDS

\section{Conclusions}

Our study model was adopted based on seven criteria to produce a subsurface water vulnerability map that shows us the weaknesses in Laylan sub-basin. After processing these criteria, a final map was produced that simulates the sum of these criteria and their effect on each other. This map is divided into 5 regions according to areas of vulnerability. Starting from the most exposed areas to the most resistant areas for pollutants to reach the groundwater. Meaning it is less weak and more resistant to contaminants. This part is characterized by the presence of permeable rocks and sediments that allow water to pass through and penetrate to reach groundwater. This area has a low slope and the rocks within this area have porosity and permeability and it makes sense to be a weak area. The first zone has an area of 43 $\mathrm{km}^{2}$, which constitutes $15.4 \%$ of the region of Laylan sub-basin. As for the next area, it constitutes about $19.2 \%$ of the study area and is less weak than its predecessors. The third band that follows the previous two bands is a band characterized by medium weakness and constitutes about $22.4 \%$ of the study area due to the different characteristics of this region. While the fourth range constitutes the largest proportion of the study area, which constitutes $29.2 \%$ of the study area, and it is a relatively weak area, meaning that it is better than its predecessors. While the good range is more resistant to pollution, which extends in the central of Laylan sub-basin and forms about 13.6\% of Laylan sub-basin. The main reason is the existing mud layers in the region were concentrated in the southern parts of the region due to the torrents that carried them and deposited them in these sites, and thus worked to prevent them. Water easily penetrated these areas on the opposite side of the north, northeast, and west of Laylan sub-basin, which represents an area with sediments and rocks, mostly sand and gravel. This allows water to penetrate easily. The groundwater vulnerability areas are located within a classification of less than 75, meaning that it is low in vulnerability. In addition, the correlation coefficient between the TDS and the DRASTIC shows a direct and high correlation, where the $\mathrm{R}^{2}$ is 0.85 . We recommended mitigating the high-risk areas for future projects, which are concentrated in the north and northwest of Laylan subbasin. 


\section{Acknowledgements}

Thanks to the staff of the Geological Department in the Al-Yama Subterranean Department in Kirkuk for providing the researcher with information and data. The authors are very grateful to the reviewers, Editor in Chief Prof. Dr. Salih M. Awadh, the Secretary of Journal Mr. Samir R. Hijab, and the Technical Editors for their great efforts and valuable comments.

\section{References}

Aller, 1., Bennet, T., Behr, J. H., Petty, R. J., and Hackett, G., 1987. Us EPA report 600/287/035, U.S. Environmental protection agency.

Al-Gburi, M. R. G., \& Al-Tamimi, O. S. I., 2020. Groundwater vulnerability assessment using drastic model of up al-khassa dam sub-basin, Kirkuk, NE Iraq. Iraqi Geological Journal, 12-24.

Al-Hayali, H. D., Al-Tamimi, O. S. I., \& Hamamin, D. F., 2021. Identification of vulnerable zones for groundwater using a GIS-based DRASTIC Technique in Shwan Sub-basin, North-Iraq. Iraqi Journal of Science, 18571597.

Rasheed, A. A., 2019. Evaluation of Groundwater in Laylan Basin, South East, Kirkuk. Unpublished Ph. D Thesis, $205 \mathrm{pp}$.

Babiker, I. S., Mohamed, M. A., Hiyama, T., \& Kato, K., 2005. A GIS-based DRASTIC model for assessing aquifer vulnerability in Kakamigahara Heights, Gifu Prefecture, central Japan. Science of the Total Environment, 345(1-3), 127-140.

Martínez-Bastida, J. J., Arauzo, M., and Valladolid, M., 2010. Intrinsic and specific vulnerability of groundwater in central Spain: the risk of nitrate pollution. Hydrogeology Journal, 18(3), 681-698.

Bera, A., Mukhopadhyay, B. P., Chowdhury, P., Ghosh, A., \& Biswas, S., 2021. Groundwater vulnerability assessment using GIS-based DRASTIC model in Nangasai River Basin, India with special emphasis on agricultural contamination. Ecotoxicology and Environmental Safety, 214, 112085.

Chenini, I., Mammou, A. B., 2010. Groundwater s recharge study in arid region: an approach using GIS techniques and numerical modeling. Computers and geosciences, 36(6), 801-817.

FAO, U., 1971. The FAO-Unesco Soil Map of the World. Legend and 9 volumes.

Jha, M. K., Chowdhury, A., Chowdary, V. M., \& Peiffer, S., 2007. Groundwater management and development by integrated remote sensing and geographic information systems: prospects and constraints. Water Resources Management, 21(2), 427-467.

Kiely, G., 1997. Environmental engineering. European Water Pollution Control, 4(7), 69.

Kozłowski, M., \& Sojka, M., 2019. Applying a modified DRASTIC Model to assess groundwater vulnerability to pollution: A case study in central Poland. Polish Journal of Environmental Studies, 28(3).

Lathamani R., Janardhana M.R. and Mahalingamc B.S., 2015 Aquatic Procedia, 4, 1031.

Le, T. N., Tran, D. X., Tran, T. V., Gyeltshen, S., Lam, T. V., Luu, T. H., \& Dao, T. V., 2021. estimating soil water susceptibility to salinization in the Mekong River Delta using a modified DRASTIC Model. Water Journal, 13(12), 1636.

Machdar, I., Zulfikar, T., Rinaldi, W., \& Alfiansyah, Y., 2018. Assessment of groundwater vulnerability using DRASTIC Model and GIS: A case study of two sub-districts in Banda Aceh city, Indonesia. In IOP Conference Series: Materials Science and Engineering, 334 (1), 012032.

Nasir, M. J., Khan, S., Zahid, H., \& Khan, A., 2018. Delineation of groundwater potential zones using GIS and multi-influence factor (MIF) techniques: a study of district Swat, Khyber Pakhtunkhwa, Pakistan. Environmental Earth Sciences, 77(10), 1-11.

Othman, A. A., Al-Maamar, A. F., Al-Manmi, D. A. M. A., Liesenberg, V., Hasan, S. E., Obaid, A. K., \& AlQuraishi, A. M. F., 2020. GIS-based modeling for selection of dam sites in the Kurdistan Region, Iraq. ISPRS International Journal of Geo-Information, 9(4), 244.

Othman, A. A., Obaid, A. K., Al-Manmi, D. A. M. A., Al-Maamar, A. F., Hasan, S. E., Liesenberg, V., \& AlSaady, Y. I., 2021. New insight on soil loss estimation in the Northwestern Region of the Zagros Fold and Thrust Belt. ISPRS International Journal of Geo-Information, 10(2), 59. 
Selvam, S., Magesh, N. S., Chidambaram, S., Rajamanickam, M., \& Sashikkumar, M. C., 2015. A GIS based identification of groundwater recharge potential zones using RS and IF technique: a case study in Ottapidaram taluk, Tuticorin district, Tamil Nadu. Environmental Earth Sciences, 73(7), 3785-3799.

Sener, E., Davraz, A., \& Ozcelik, M., 2005. An integration of GIS and remote sensing in groundwater investigations: a case study in Burdur, Turkey. Hydrogeology Journal, 13(5-6), 826-834.

Smith, P., House, J. I., Bustamante, M., Sobocká, J., Harper, R., Pan, G., \& Pugh, T. A., 2016. Global change pressures on soils from land use and management. Global Change Biology, 22(3), 1008-1028.

Thapa, R., Gupta, S., Guin, S., \& Kaur, H., 2017. Assessment of groundwater potential zones using multiinfluencing factor (MIF) and GIS: a case study from Birbhum district, West Bengal. Applied Water Science, 7(7), 4117-4131. 